\title{
Periodic EEG patterns: importance of their recognition and clinical significance
}

\author{
Padrões eletrencefalográficos periódicos: importância do seu reconhecimento e \\ significado clínico
}

Maria Emilia Cosenza Andraus', Cesar Fantezia Andraus², Soniza Vieira Alves-Leon³

\begin{abstract}
Periodic electroencephalographic (EEG) patterns consist of discharges usually epileptiform in appearance, which occur at regular intervals, in critical patients. They are commonly classified as periodic lateralized epileptiform discharges (PLEDs), bilateral independent PLEDs or BIPLEDs, generalized epileptiform discharges (GPEDs) and triphasic waves. Stimulus-induced rhythmic, periodic or ictal discharges (SIRPIDs) are peculiar EEG patterns, which may be present as periodic discharges. The aim of this study is to make a review of the periodic EEG patterns, emphasizing the importance of their recognition and clinical significance. The clinical significance of the periodic EEG patterns is uncertain, it is related to a variety of etiologies, and many authors suggest that these patterns are unequivocally epileptogenic in some cases. Their recognition and classification are important to establish an accurate correlation between clinical, neurological, laboratorial and neuroimaging data with the EEG results.
\end{abstract}

Key words: electroencephalography, PLEDs, BIPLEDs, GPEDs, triphasic waves, SIRPIDs.

\section{RESUMO}

Padrões eletrencefalográficos (EEG) periódicos consistem em descargas geralmente epileptiformes em aparência, que ocorrem a intervalos regulares, em pacientes críticos. Esses padrões são habitualmente classificados como descargas epileptiformes periódicas lateralizadas (PLEDs), PLEDs bilaterais e independentes ou BIPLEDs, descargas epileptiformes periódicas generalizadas (GPEDs) e ondas trifásicas. Descargas rítmicas, periódicas ou ictais induzidas por estímulos (SIRPIDs) são padrões eletrencefalográficos peculiares, que podem se apresentar como descargas periódicas. O objetivo deste estudo é fazer uma revisão dos padrões EEG periódicos, enfatizando a importância do seu reconhecimento e seu significado clínico. O significado clínico dos padrões EEG periódicos é incerto. Está relacionado a uma variedade de etiologias e muitos autores sugerem que tais padrões sejam inequivocamente de natureza epileptogênica em alguns casos. 0 seu reconhecimento e classificação são importantes para estabelecer uma correlação acurada entre dados clínicos, neurológicos, laboratoriais e de neuroimagem com os resultados de EEG.

Palavras-Chave: eletroencefalografia, PLEDs, BIPLEDs, GPEDs, ondas trifásicas, SIRPIDs.

The term "periodic" was first used by Cobb et al. ${ }^{1}$, in 1950, to describe periodically occurring discharges in electroencephalograms (EEG) of 5 patients with subacute progressive encephalitis. Periodic EEG patterns consist of various forms discharges, usually epileptiform in appearance, and apply to waves or complexes occurring in sequence at an approximately regular rate or intermittently regular intervals ${ }^{2,3}$. They are commonly classified as periodic lateralized epileptiform discharges (PLEDs), bilateral independent PLEDs or BIPLEDs, generalized epileptiform discharges (GPEDs) and triphasic waves ${ }^{2-7}$. Although not always epileptiform in appearance, triphasic waves are periodic and generalized, and the category of generalized periodic discharges also includes them ${ }^{2}$. PLEDs may be subclassified into PLEDs-proper and PLEDs-plus, and GPEDs into periodic short-interval diffuse discharges (PSIDDs) and periodic long-interval diffuse discharges (PLIDDs) ${ }^{3,5}$. Stimulus-induced rhythmic, periodic or ictal discharges (SIRPIDs) consist on peculiar EEG patterns, which were described more recently, and may be present as periodic discharges ${ }^{2,3,8}$.

1 Electroencephalography Section, Service of Neurology of Prof. Sérgio Novis, $24^{\text {th }}$ and $25^{\text {th }}$ Infirmaries, Santa Casa da Misericórdia do Rio de Janeiro, Rio de Janeiro RJ, Brazil. Permanent Professor of Strictu Sensu Post Graduation Program in Neurology, Universidade Federal do Estado do Rio de Janeiro (UNIRIO), Rio de Janeiro RJ, Brazil;

${ }^{2}$ Neurosurgery Service, Hospital Universitário Clementino Fraga Filho, Universidade Federal do Rio de Janeiro (HUCFF-UFRJ), Rio de Janeiro RJ, Brazil; ${ }^{3}$ Epilepsy Program, Service of Neurology, HUCFF-UFRJ, Rio de Janeiro RJ, Brazil. Associate Professor of Neurology and Permanent Professor of Strictu Sensu Post Graduation Program in Neurology, UNIRIO, Rio de Janeiro RJ, Brazil.

Correspondence: Maria Emilia Cosenza Andraus; Santa Casa da Misericórdia do Rio de Janeiro - Setor de Eletroencefalografia, Serviço de Neurologia do Prof. Sérgio Novis, 25ªnfermaria; Rua Santa Luzia 206; 20020-022 Rio de Janeiro RJ - Brasil; E-mail: cosenzaandraus@yahoo.com

Conflict of interest: There is no conflict of interest to declare.

Received 22 June 2011; Received in final form 19 October 2011; Accepted 26 October 2011 
Periodic EEG activity is commonly observed in critical patients, especially in the intensive care unit (ICU) setting, but, except for SIRPIDs, this terminology has been based primarily on routine 20-30 minute EEG recordings ${ }^{2,3,8}$. They are indicative of significant acute or subacute brain impairment and may be lateralized or generalized ${ }^{2,3}$. Periodic discharges should direct the attention to the high potential for seizures and convulsive or nonconvulsive status epilepticus, and many authors recommend the use of conventional antiepileptic drugs (AEDs) to manage any occurrence of these discharges ${ }^{3,9}$. Sometimes, however, the discharges are not actually epileptiform in appearance nor epileptogenic in nature ${ }^{3,10}$. This is one of the reasons for the "E" of "epileptiform" is no more recommended by the American Clinical Neurophysiology Society (ACNS) Critical Care Monitoring Committee nomenclature, that proposed the term lateralized periodic discharges (LPDs) to name PLEDs, bilateral independent periodic discharges (BIPDs) to name BIPLEDs, and generalized epileptiform discharges (GPDs) to name GPEDs ${ }^{10}$. This nomenclature, however, is still undergoing testing and revision, and we preferred to keep the most known and consecrated nomenclature. A fixed interval between the discharges is relatively rare, and some authors prefer to name them pseudoperiodic or quasi-periodic discharges although this separation is not considered clinically relevant ${ }^{2,5,10-12}$.

A review was performed trying to show and understand the importance and clinical significance of the periodic EEG patterns, and to expose the strength of data on which management of recommendations have been based. Because periodic patterns are considered controversial EEG patterns, and are present in critical patients, who need therapeutic interventions based on decisions making, we considered it a relevant topic to review. We included SIRPIDs in this review for they are relatively new described EEG patterns which may present as periodic discharges.

\section{Periodic Lateralized Epileptiform Discharges - PLEDs}

PLEDs are the most common and the most periodic EEG pattern that have been studied ${ }^{2,5,13}$. This term was first used by Chatrian et al. ${ }^{14}$, in 1964, to describe a pattern consisting of sharp waves and/or spikes, associated or not with slow waves, or other complex wave forms, occurring at periodic intervals. They consist of lateralized complexes, usually recurring every 1.0 to 2.0 seconds, and often (but not always) appear as sharp waves or spikes which may be followed by a slow wave ${ }^{2-4}$. Cobb et al. ${ }^{1}$, in 1950, attributed the periodicity of the discharges to a disconnection of the cortex from the subcortical structures, usually caused by a large white matter lesion. After that, Chatrian et al. ${ }^{14}$, through experimental studies with pathological specimens, showed that a lesion anywhere can be associated with PLEDs. Some authors hypothesized that PLEDs could be the EEG manifestation of an abnormal response of neurons, which changes their excitatory neurotransmission in cases of acute brain lesions ${ }^{15}$. The cells would either recover and respond normally or die after a period of time, no longer responding, and thereby leading to the disappearance of PLEDs recorded in the EEG ${ }^{15,16}$. Thus, they could be considered a nonspecific result of acute partial and transient functional denervation in a localized area of the cortex ${ }^{15}$.

Reiher et al. ${ }^{17}$ proposed a subclassification of PLEDs in two major groups: PLEDs-proper, in which the periodicity of the discharges is relatively stable, the discharges are simply configured and uniform, and there are no associated rhythmic discharges; and PLEDs-plus, in which the periodicity of the discharges is variable and there is associated low amplitude rhythmic activity with the discharges. It seems that PLEDsplus pattern is more associated with seizures, but few studies suggested significant risk stratification for it $^{2,15,17}$. Chong et al. ${ }^{2}$ reported their experience with 24-hour continuous EEG recordings (coEEG) and observed that PLEDs-proper rarely occurs in isolation, with the EEG typically fluctuating between PLEDs-proper and PLEDs-plus, with high seizures risk in these patients.

PLEDs are indicative of an acute non-specific brain dysfunction or unilateral brain lesion, usually destructive, and they are most often present in cases of cerebral infarction ${ }^{2,5,15}$. They have also been described in the presence of fast-growing brain tumors (as glioblastoma multiforme), brain abscesses, viral encephalitis (especially related to the Herpes simplex virus), Creutzfeldt-Jakob disease (CJD), hematomas and, less frequently, in demyelinating diseases, anoxia, primary epilepsia, migraine and fat embolism syndrome, among others ${ }^{2,15,18-23}$. Sekiguchi et al. ${ }^{24}$ described a case of PLEDs in an infant with congenital protein $\mathrm{C}$ deficiency. In cerebral infarction, PLEDs are usually recorded on the area adjacent to infarction, which is partially affected by the disease process and is able to generate electrical activity (unlike the area directly affected by infarction), but whether these cells are apoptotic or regenerating is unknown ${ }^{2,3}$. Neufeld et al. ${ }^{20}$ and Chu et al. ${ }^{25}$ emphasized the importance of the presence of an structural brain lesion associated with metabolic disturbances in the production of PLEDs.

PLEDs tend to be transient and resolve spontaneously within 2 to 3 weeks, the discharges tend to decrease in amplitude, the repetition rate decreases and then the discharges cease $2,3,9,11,26-28$. Chronic PLEDs, however, have been reported in patients with chronic epilepsy or old static lesions, especially related to recent seizures, alcohol withdrawal or chronic toxic-metabolic disturbances ${ }^{4,7,9,11,14,15,26}$. The major controversy about PLEDs is whether they are ictal, interictal or a postictal phenomenon ${ }^{2,3,9,15,23}$. Many authors consider that PLEDs is a reflection of an acute cerebral damage, associated or not with seizures depending on many factors, such as the individuals propensity for seizures, the underlying process and the coexistence of metabolic disturbances, and that the outcome is more related to age and etiology than to 
specific periodic EEG pattern ${ }^{9,15,28}$. Garzon et al. ${ }^{9}$ performed a prospective and clinical study in 55 patients, with a total of 62 status epilepticus and 254 ictal/postictal EEG recordings, and analyzed the relationship between PLEDs and status epilepticus. They demonstrated that, although PLEDs were not always associated with seizures and status epilepticus, they can be unequivocally an ictal pattern. Increased focal glucose metabolism has been demonstrated associated with PLEDs, reinforcing their probable epileptogenic nature ${ }^{27}$. Although they indicate an ictal pattern in some cases, PLEDs are usually considered an interictal change or an unstable ictal-interictal continuum ${ }^{2,3}$.

PLEDs are usually associated with obtundation in 95\% of patients, focal seizures and focal neurological signs may occur in $80 \%$, and epilepsia partialis continua in $30 \%$ of the patients ${ }^{14,23}$. Clinical seizures or status epilepticus were seen during the course of illness in $126(90 \%)$ patients in a study performed by Snodgrass et al..$^{29}$, with $50 \%$ presenting partial motor status epilepticus, $22 \%$ partial motor seizures, $6 \%$ epilepsia partialis continua, $6 \%$ isolated generalized seizures and $8 \%$ generalized status epilepticus. The prevalence of PLEDs in routine EEG laboratories ranges from $0.1 \%$ to $1 \%^{13-15,30}$.

\section{Bilateral Periodic Lateralized Epileptiform Discharges - BIPLEDs}

BIPLEDs occur when PLEDs are seen in both hemispheres, in an independent and asynchronous manner ${ }^{2,531}$. This pattern is less common than PLEDs and is highly associated with seizures in acutely ill patients ${ }^{2}$. In contrast to PLEDs, BIPLEDs may present as asynchronous complexes, usually differing in morphology, amplitude, rate of repetition, and site of maximal involvement ${ }^{4}$. BIPLEDs are typically associated with acute structural lesions, with or without metabolic disturbances ${ }^{2,7,32}$. The most common causes of BIPLEDs are anoxic encephalopathy and central nervous system infection, with a high incidence of coma state ${ }^{7,32}$. Few studies demonstrated that clinical state and prognosis may be worse than with PLEDs, but a case of benign BIPLEDs has also been reported ${ }^{4,5,28,30}$. In a study with 21 patients with BIPLEDs, Fitzpatrick et al..$^{30}$ demonstrated a mortality rate of $52 \%$, and De La Paz et al. ${ }^{32}$, studying 21 patients too, demonstrated a mortality rate of $61 \%$. The true prevalence and incidence of BIPLEDs are unknown, with studies reporting an incidence of $4 \%$ to $22 \%$ in patients in the ICU, and a prevalence of $0.1 \%$ in routine EEG laboratories ${ }^{11,14,30}$.

\section{Generalized Periodic Epileptiform Discharges - GPEDs}

GPEDs are defined as periodic complexes occupying at least $50 \%$ of a standard 30-minute EEG, projected over the both hemispheres, in a symmetric, diffuse and synchronous manner (although they may be more prominent in a given region, frequently the anterior regions $)^{5,13}$. The discharges vary in shape, but usually are characterized by spikes or sharp waves of high amplitude ${ }^{2,3}$. They are usually classified as PSIDDs and PLIDDs ${ }^{2,5,7,32-34}$. According to the interval between the discharges, the burst suppression pattern may be present as GPEDs too ${ }^{7,33}$. PSIDDs have a periodicity less than 4.0 seconds and are more common and less specific than PLIDDs $^{5,33}$. Generally, PSIDDs are associated to toxic-metabolic encephalopathies, anoxic brain injury, CJD and subclini-

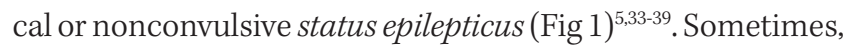
it is difficult to distinguish the etiology of GPEDs, even with history and clinical findings suggesting or not an epileptic or toxic-metabolic etiology ${ }^{34,38-40}$. Central nervous system infection, as neurosyphilis, has been described in association with GPEDs in patients with cognitive and behavioral disorders ${ }^{41}$. In a study with 25 patients presenting GPEDs, Husain et al. ${ }^{35}$ reported that 7 (28\%) of them had toxic-metabolic encephalopathy, 10 (40\%) had anoxia and toxic-metabolic encephalopathy, 8 (32\%) had a primarily neurological process, and $8(32 \%)$ were in status epilepticus. In practice, a clinical trial with AEDs is almost always warranted to differentiate nonconvulsive status epilepticus from severe encephalopathies although most patients will not respond clinically or electrographically ${ }^{39,40}$.

Gloor et al ${ }^{42}$ suggested that the periodicity of the discharges might be related to the recovery cycle of both cortical and subcortical structures, and that the subcortical discharges may be responsible for the surface discharges, but their repetition rate depends upon cortical recovery time. They proposed an abnormal functional state in the central nervous system, permitting rapid generalization of neuronal discharges.

In the CJD, the classic EEG patterns usually are characterized by PSIDDs, with biphasic or triphasic sharp waves, with a duration of 100-300 milliseconds and recurring at 0.7-1.5 second interval between the discharges, with symmetric and synchronous widespread ${ }^{43}$. Traub et al. ${ }^{44}$ suggested, through experimental evidence and computer modeling, that synchrony and periodicity in the CJD may be related to a virus-induced fusion of neuronal processes, particularly dendrites, leading to an abnormal electrotonic coupling between cells, providing the basis for powerful excitatory interaction whereby large neuronal aggregates burst in near synchrony. Cortical synchronous discharges would give rise to sharp waves in the EEG, whereas similar discharges in brainstem, spinal cord or elsewhere could lead to myoclonic jerks.

It is worth remembering, however, that the bioelectric cerebral activity is a dynamic process, with temporal variations and transient patterns, which could difficult the correct interpretation and show the necessity of serial EEGs in some cases, to establish the correct clinical and EEG correlation $^{35,43}$. In the early course of the CJD, diffuse slowing is the most common EEG finding, with GPEDs becoming evident within months after clinical onset, sometimes evolving from PLEDs (Fig 2A-2B) ${ }^{2,33}$. The clinical and EEG features 
in the early stages of CJD may resemble nonconvulsive status epilepticus too ${ }^{35}$. The clinical and EEG correlation, response to AEDs and monitoring with serial EEG recordings may be helpful considerations in the differential diagnosis ${ }^{35,45-47}$.

PLIDDs usually have a frequency of at least 4.0 seconds between the discharges ${ }^{48,49}$. They are more specific with respect to the etiology and may be encountered in disorders like some toxic encephalopathies (for baclofen or ketamine, for example), anoxic brain injury and $\mathrm{SSPE}^{3}$. In SSPE (suggested by the presence of PLIDDs in a child with dementia and myoclonic jerks), the stereotyped complexes, occurring at a regular interval and having a constant relationship to myoclonus, make this as one of the most characteristic and disease-specific of all EEG patterns ${ }^{34,48-51}$. The early descriptions, by $\mathrm{Cobb}^{48}$, in 1966, characterized the stage II of SSPE by bilaterally symmetrical and synchronous generalized, stereotyped high amplitude delta waves, called Radermacker or "R" complexes, recurring at regular intervals of 5 to 15 seconds, although less specific and atypical EEG changes have been described $^{49}$. With advancing disease, the interval between the discharges becomes progressively smaller ${ }^{2,49}$. Silva et al. ${ }^{51}$ described an atypical clinical and EEG pattern in a 14-yearold boy with SSPE, who presented an initial EEG characterized by a left temporal focus which evolved to PLEDs. Typical GPEDs appeared during the $3^{\text {rd }}$ and $4^{\text {th }}$ weeks.
GPEDs are an uncommon EEG pattern with an overall incidence between $0.4 \%$ and $1 \%$ in EEG laboratory series ${ }^{3}$. It seems that more than $50 \%$ of patients with GPEDs have definite seizures during the acute illness ${ }^{3}$.

\section{Triphasic waves}

Generalized periodic discharges also include triphasic waves, a pattern initially described in 1950 by Foley et al. ${ }^{52}$, who named the waves as "blunted and spike waves". Triphasic waves are periodic and generalized, typically frontally predominant and not always epileptiform in appearance (a reason for they are often not included in the GPEDs categorization $)^{2,5}$. This pattern can occur in any toxic-metabolic or structural encephalopathy although the early descriptions associated its presence to hepatic encephalopathy ${ }^{3,6,35}$. The three most common causes of triphasic waves are hepatic encephalopathy, renal failure (Fig 3) and anoxic injury ${ }^{6}$. This term was coined by Bickford et al. ${ }^{53}$, in reference to the typical morphology, characterized by three phases. They consist of generalized periodic sharp waves or sharply contoured delta waves with a triphasic morphology (typically with a negative/positive/negativity polarity, with each phase lasting longer than the prior), recurring at 1.0 to $3.0 \mathrm{~Hz}$, with or without an anterior-posterior or posterior-anterior lag. When the term triphasic waves is used, it usually implies a pattern

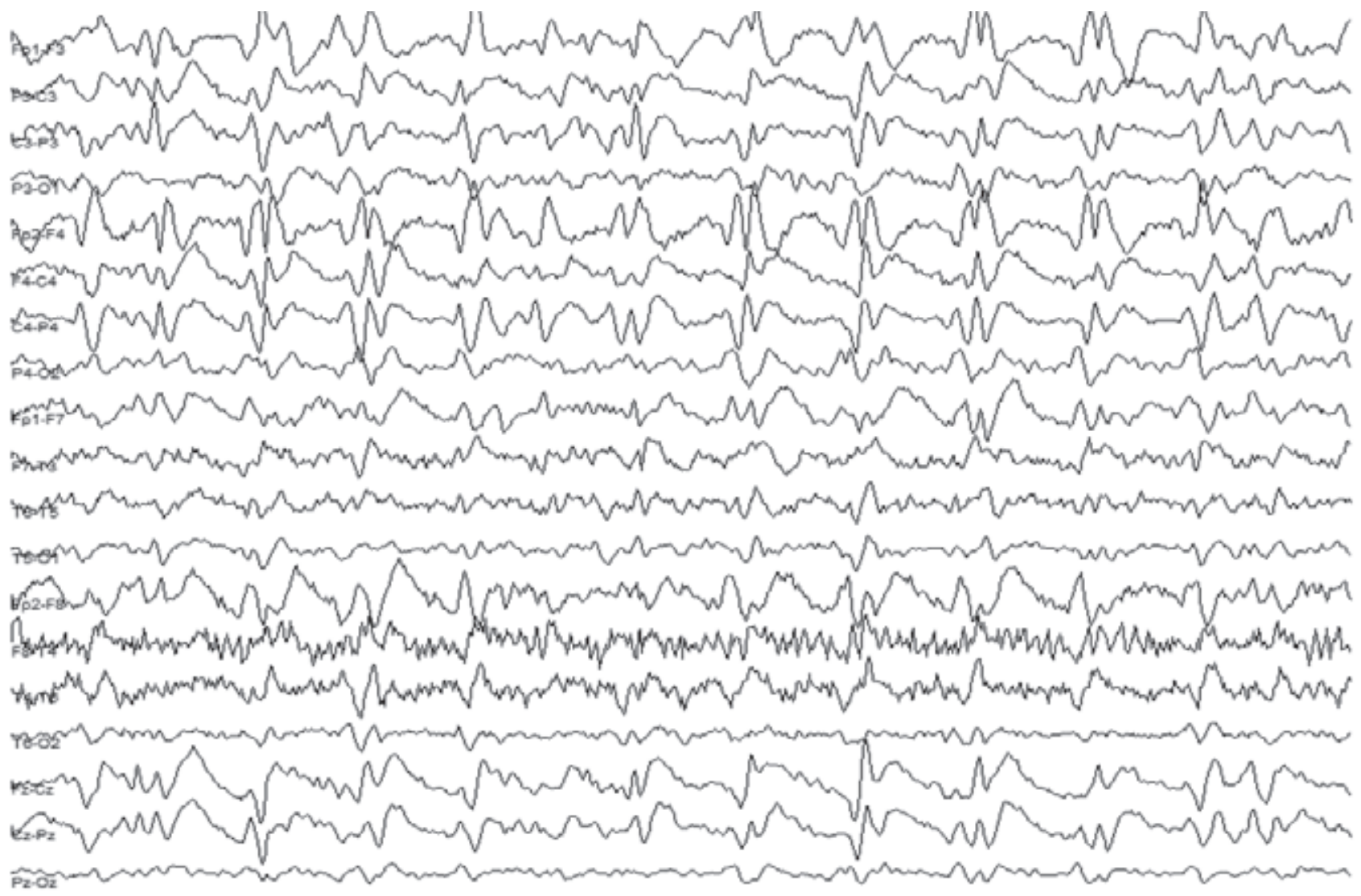

Fig 1. Generalized periodic discharges (GPEDs) in an EEG of a 72-year-old woman with epilepsy, presenting an altered mental status due to nonconvulsive status epilepticus. 
seen with a variety of encephalopathies, particularly hepatic or renal ${ }^{4}$. It is worth to remember, however, that this term can be used to describe the morphology of waveform in that sharp and slow wave three phases complexes.

Sometimes, when patients present confused and obtunded and rhythmic sharp waves resembling triphasic waves appear in the EEG, it is difficult to distinguish nonconvulsive status epilepticus from toxic-metabolic encephalopathy ${ }^{4,54}$. In these situations, some authors recommend the use of benzodiazepines administration to verify the resolution of EEG changes in the cases of nonconvulsive status epilepticus even though thriphasic waves may be abolished by benzodiazepines administration, as demonstrated by Foutain et al. ${ }^{54}$. Boulanger et al. ${ }^{55}$ compared the 87 EEGs of 71 patients with triphasic waves and 27 EEGs of 13 patients with nonconvulsive status epilepticus, and showed that, when compared to triphasic waves, epileptiform discharges associated with nonconvulsive status epilepticus had a higher frequency, a

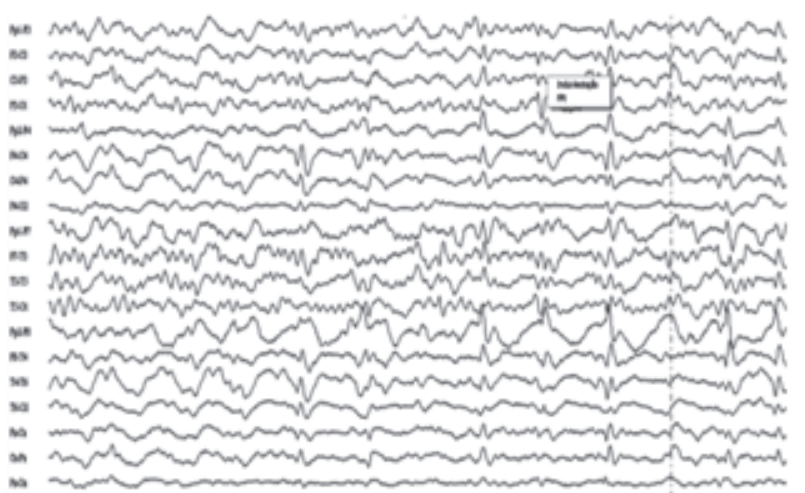

A

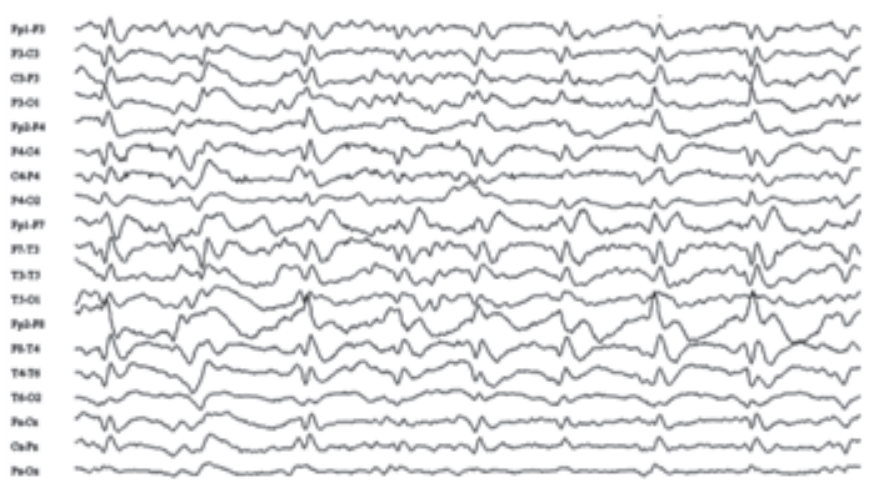

B

Fig 2. Periodic lateralized epileptiform discharges (PLEDs) in the right hemisphere, predominantly over the frontotemporal regions (A), with some widespread, evolving to generalized periodic epileptiform discharges (GPEDs) (B) in an EEG of a 50-year-old woman with rapidly progressive cognitive impairment, altered mental status and muscle spasms. The clinical picture, the neuroimaging studies, the absence of toxic-metabolic disorders and no improvement with antiepileptic drug allied to the EEG periodic patterns supported the presumptive diagnosis of Creutzfeldt-Jakob disease.

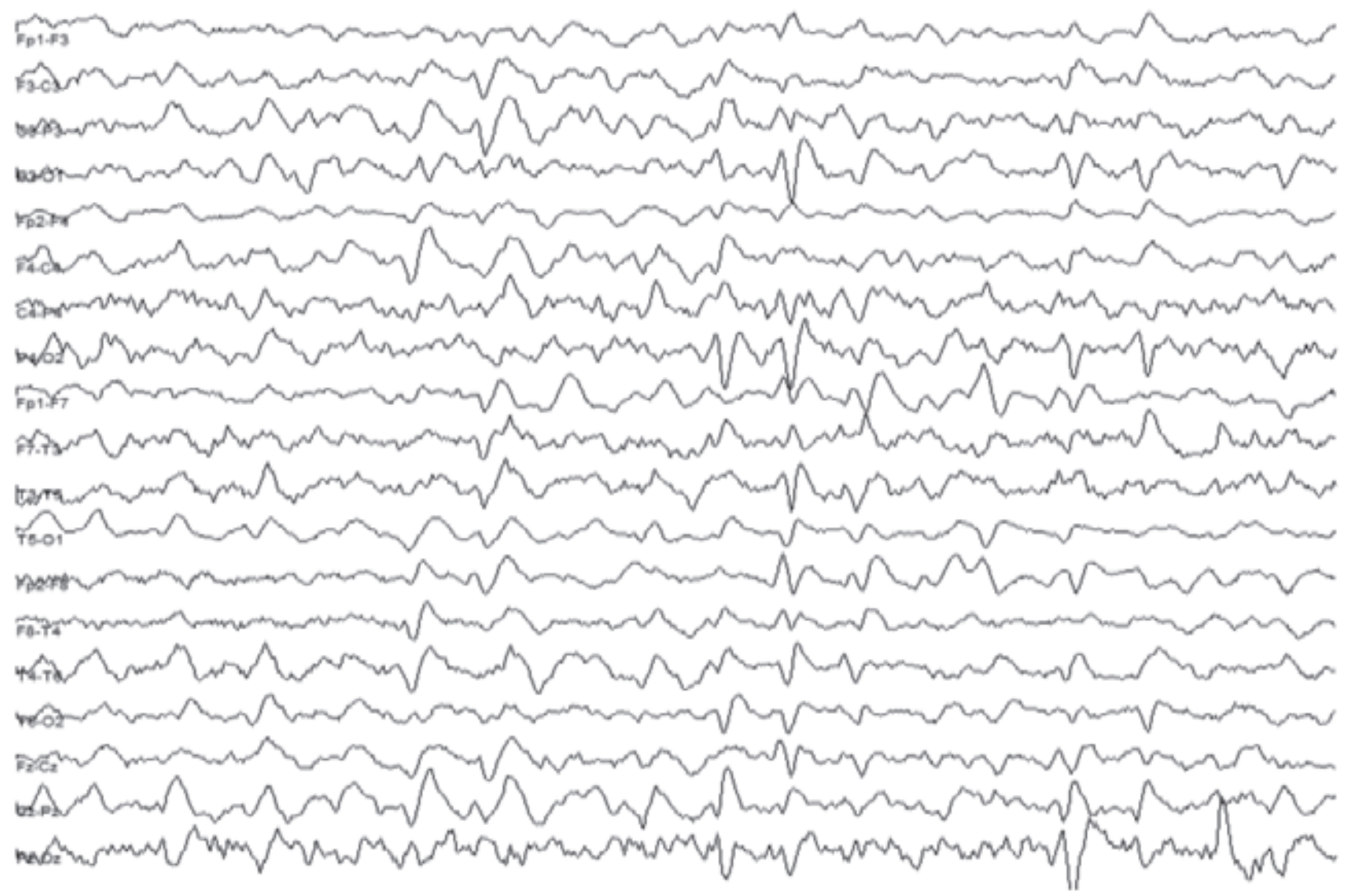

Fig 3. Pseudoperiodic runs of triphasic sharp waves in a background generalized slowing EEG. This record corresponds to a metabolic (renal failure) encephalopathy in a 69-year-old man, presented with an altered mental status. 
shorter duration of phase one, extra-spikes components and less generalized background slowing. Noxious or auditory stimulation frequently increased the triphasic waves and had no effect on the epileptiform pattern. The authors concluded that certain EEG criteria and the response to stimulation are very helpful in distinguishing triphasic waves from generalized nonconvulsive status epilepticus.

\section{Stimulus-induced Rhythmic, Periodic or Ictal Discharges - SIRPIDs}

SIRPIDs were first described in 2004 by Hirsch et al. ${ }^{8}$, who recorded coEEG and digital video in critical patients in the ICU setting. They have noted striking EEG patterns when stuporous or comatose patients were stimulated and noted that many of these patterns appear ictal, but were consistently elicited by stimulation. They named these EEG patterns as SIRPIDs and defined them as periodic, rhythmic or ictal appearing discharges that were consistently induced by alerting stimuli, such as auditory, sternal rub, examination, suctioning, turning and other patient-care activity. They consider SIRPIDs as periodic when the pattern consist of epileptiform discharges recurring at regular or nearly regular intervals, with an identifiable interdischarge interval. The specific periodic patterns were classified as periodic epileptiform discharges (PEDs) and subdivided in PLEDs, BIPLEDs, GPEDs and triphasic waves. Some patients present clinical seizures with SIRPIDs, especially focal motor seizures, but this pattern is usually a purely electrographic change, with no obvious clinical manifestations ${ }^{2,8,10}$. The pathophysiology, exact clinical, therapeutic and prognostic significance of SIRPIDs is still undefined ${ }^{2,8,10}$.

\section{Final remarks}

The clinical significance of the periodic EEG patterns remains uncertain. Many authors suggest that they are unequivocally epileptogenic in some cases, and how aggressive to treat them with AEDs is still unclear. A clinical trial with AEDs to treat a possible nonconvulsive status epilepticus is indicated on the majority of the cases although most patients will not respond clinically or electroencephalographically.

Periodic patterns are seen from a wide variety of etiologies, and the discharges themselves are electrographically heterogeneous. So, the patients should be carefully investigated for toxic-metabolic, infectious diseases and/or intracranial lesions, and nonconvulsive status epilepticus should be considered. Their recognition is important to try to establish an accurate correlation between clinical, neurological, laboratorial and neuroimaging data with the EEG results and to guide the decisions making.

\section{References}

1. Cobb W, Hill D. Electroencephalogram in subacute progressive encephalitis. Brain 1950;73:392-404.

2. Chong DJ, Hirsch LJ. Which EEG patterns warrant treatment in the critically ill? Reviewing the evidence for treatment of periodic epileptiform discharges and related patterns. J Clin Neurophysiol 2005;22:79-91.

3. Hirsch LJ, Brenner RP. Periodic discharges and other controversial EEG patterns. In: Hirsch LJ, Brenner RP (Eds). Atlas of EEG in critical care. Chichester: Wiley-Blackwell, 2010:129-160.

4. Brenner RP. EEG in convulsive and nonconvulsive status epilepticus.J Clin Neurophysiol 2004;21:319-331.

5. Brenner RP, Schaul N. Periodic EEG patterns: classification, clinical correlation and pathophysiology. J Clin Neurophysiol 1990;7:249-267.

6. Brigo F, Storti M. Triphasic waves. Am J Eletroneurodiagnostic Technol 2011:51:16-25.

7. Orta DSJ, Chiappa KH, Quiroz AZ, Costello DJ, Cole AJ. Prognostic implications of periodic epileptiform discharges. Arch Neurol 2009;66:985-991.

8. Hirsch LJ, Claassen J, Mayer SA, Emerson RG. Stimulus-induced rhythmic, periodic, or ictal discharges (SIRPIDs): a common EEG phenomenon in the critically ill. Epilepsia 2004;45:109-123.

9. Garzon E, Fernandes RM, Sakamoto AC. Serial EEG during human status epilepticus: evidence for PLED as an ictal pattern. Neurology 2001;57:1175-1183.

10. Hirsch LJ, Brenner RP, Drislane FW, et al. The ACNS subcommittee on research terminology for continuous EEG monitoring: proposed standardized terminology for rhythmic and periodic EEG patterns encountered in critically ill patients. J Clin Neurophysiol 2005;22:128-135.

11. Gross DW, Wiebe S, Blume WT. The periodicity of lateralized epileptiform discharges. Clin Neurophysiol 1999;110:1516-1520.
12. Markand ON, Daly DD. Pseudoperiodic lateralized paroxysmal discharges in electroencephalogram. Neurology 1971;21:975-981.

13. Kuroiwa Y, Celesia GG. Clinical significance of periodic EEG patterns. Arch Neurol 1980;37:15-20.

14. Chatrian GE, Shaw CM, Leffman H. The significance of periodic lateralized epileptiform dischages in EEG: an electrographic, clinical and pathological study. Electroencefalogr Clin Neurophysiol 1964:17:177-193.

15. García-Morales I, García MT, Galán-Dávila L, et al. Periodic lateralized epileptiform discharges: etiology, clinical aspects, seizures, and evolution in 130 patients. J Clin Neurophysiol 2002;19:172-177.

16. Gross DW, Quesney LF, Sadikot AF. Chronic periodic lateralized epileptiform discharges during sleep in a patient with caudate nucleus atrophy: insights into the anatomical circuitry of PLEDs. Electroencephalogr Clin Neurophysiol 1998;107:434-438.

17. Reiher J, Rivest J, Grand'Maison F, Leduc CP. Periodic lateralized epileptiform discharges with transitional rhythmic discharges: association with seizures. Electroencephalogr Clin Neurophysiol 1991;78:12-17.

18. Jacome DE. Periodic EEG patterns in cerebral fat embolism. Clin Electroencephalogr 1983;14:27-34.

19. Au WJ, Gabor AJ, Vijayan N, Markand ON. Periodic lateralized epileptiform complexes (PLEDs) in Creutzfeldt-Jakob disease. Neurology 1980;30:611-617.

20. Neufeld MY, Vishnevskaya S, Treves TA, et al. Periodic lateralized epileptiform discharges (PLEDs) following stroke are associated with metabolic abnormalities. Electroencephalogr Clin Neurophysiol 1997:102:295-298.

21. Pohlmann-Eden B, Hoch DB, Cochius JI, Chiappa KH. Periodic lateralized epileptiform discharges: a critical review. J Clin Neurophysiol 1996;13:519-530. 
22. de los Reyes EC, McJunkin JE, Glauser TA, Tomsho M, O'Neal J. Periodic lateralized epileptiform discharges in La Crosse encephalitis, a worrisome subgroup : clinical presentation, electroencephalogram (EEG) patterns, and long-term neurologic outcome. J Child Neurol 2008;23:167-172.

23. Gandelman-Marton R, Rabey JM, Flechter S. Periodic lateralized epileptiform discharges multiple sclerosis: a case report. J Clin Neurophysiol 2003;20(2):117-121.

24. Sekiguchi K, Akiyoshi K, Okazaki N, et al. PLEDs in an infant with congenital protein C deficiency: a case report. Clin Neurophysiol 2010;121:800-801.

25. Chu NS. Periodic lateralized epileptiform discharges with preexisting focal brain lesions. Role of alcohol withdrawal and anoxic encephalopathy. Arch Neurol 1980;37:551-554.

26. Westmoreland BF, Klass DW, Sharbrough FW. Chronic periodic lateralized epileptiform discharges: electrographic and clinical features. Arch Neurol 1986;43:494-496.

27. Handfort A, Cheng JT, Mandelkern MA, Treiman DM. Markedly increased mesiotemporal lobe metabolism in a case with PLEDs: further evidence that PLEDs are a manifestation of partial status epilepticus. Epilepsia 1994;35:876-881.

28. Silva AB, Bertolucci PHF. Descargas periódicas lateralizadas II. Aspectos evolutivos. Arq Neuropsiquiatr 1988;46:10-15.

29. Snodgrass SM, Tsuburaya K, Ajmone-Marsan C. Clinical significance of periodic lateralized epileptiform discharges: relationship with status epilepticus. J Clin Neurophysiol 1989;6:159-172.

30. Fitzpatrick W, Lowry N. PLEDs: clinical correlates. Can J Neurol Sci 2007;34:443-450.

31. Fushimi M, Matsubuchi N, Sekine A, Shimizu T. Benign bilateral independent periodic lateralized epileptiform discharges. Acta Neurol Scand 2003;108:55-59.

32. De La Paz D, Brenner RP. Bilateral independent periodic lateralized epileptiform discharges. Clinical significance. Arch Neurol 1981;38:713-715

33. Yemisci M, Gurer G, Saygi S, Ciger A. Generalised periodic epileptiform discharges: clinical features, neuroradiological evaluation and prognosis in 37 adult patients. Seizure 2003;12:465-472.

34. Gaches J. Activités périodiques en EEG. Rev EEG Neurophysiol Clin 1971;1:9-33

35. Husain AM, Mebust KA, Radtke RA. Generalized periodic epileptiform discharges: etiologies, relationship to status epilepticus, and prognosis. J Clin Neurophysiol 1999;16:51-58.

36. Fernández-Torre JL, Solar DM, Astudillo A, Cereceda R, Acebes A, Calatayud MT. Creutzfeld-Jakob disease and non-convulsive status epilepticus: a clinical and electroencephalographic follow-up study. Clin Neurophysiol 2004;115:316-319.

37. Wang PS, Wu YT, Hung Cl, Kwan SY, Teng S, Soong BW. Early detection of periodic sharp wave complexes on EEG by independent analysis in patients with Creutzfeldt-Jakob disease. J Clin Neurophysiol 2008;25:25-31.

38. Drislane FW, Lopez MR, Blum AS, Schomer DL. Detection and treatment of refractory status epilepticus in the intensive care unit. J Clin Neurophysiol 2008;25:181-186.

39. Korabathina K, Benbadis SR. EEG diagnosis of nonconvulsive status epilepticus: generalized periodic patterns - status or not? Expert Rev Neurother 2007;7:1643-1644.

40. Parkerson KA, Reinsberger C, Chou SH, Dworetzky BA, Lee JW Lacosamide in the treatment of acute recurrent seizures and periodic epileptiform patterns in critically ill patients. Epilepsy Behav 2011;20:48-51.

41. Anghinah R, Camargo EC, Braga NI, Waksman S, Nitrini R. Generalized periodic EEG activity in two cases of neurosyphilis. Arq Neuropsiquiatr 2006;64:122-124.

42. Gloor P, Kalabay O, Giard N. The electroencephalogram in diffuse encephalopathies: electroencephalographic correlates of gray and white matter lesions. Brain 1968;91:779-802.

43. Ortega-AlbásJJ, Serrano-García AL. Neurofisiología en la enfermedad de Creutzfeldt-Jakob. Rev Neurol 2003;36:376-380,

44. Traub RD, Pedley TA. Virus-induced electrotonic coupling: hypothesis on the mechanism of periodic EEG discharges in Creutzfeldt-Jakob disease. Ann Neurol 1981;10:405-410.

45. Lapergue B, Demeret S, Denys V, et al. Sporadic Creutzfeldt-Jakob disease mimicking nonconvulsive status epilepticus. Neurology 2010;74:1995-1999.

46. Bouwman NA, Verhagen WI, Meulstee J. EEG abnormalities in poikilothermia suggesting Creutzfeldt-Jakob disease. Clin EEG Neurosci 2009;40:196-199.

47. Hansen HC, Zschocke S, Stürenburg HJ, Kunze K. Clinical changes and EEG patterns preceding the onset of periodic sharp wave complexes in Creutzfeldt-Jakob disease. Acta Neurol Scand 1998;97:99-106.

48. Cobb W. The periodic events of subacute sclerosing leucoencephalitis. Electroencephalogr Clin Neurophysiol 1966;21:278-294.

49. Praaven-kumar S, Sinha S, Taly AB, et al. Electroencephalographic and imaging profile in a subacute sclerosing panencephalitis (SSPE) cohort: a correlative study. Clin Neurophysiol 2007;118:1947-1954.

50. Bertolucci PH, Silva AB. Descargas epileptiformes lateralizadas 1. Aspectos clínicos e eletrencefalográficos. Arq Neuropsiquiatr 1987;45:364-370.

51. Silva DF, Lima MM, Anghinah R, Zanoteli E, Lima JGC. Atypical clinical and electroencephalographic pattern in a patient with subacute sclerosing panencephalitis. Arq Neuropsiquiatr 1995;53:278-280.

52. Foley JM, Watson CW, Adams RD. Significance of the electroencephalographic changes in hepatic coma. Trans Am Neurol Assoc 1950;51:161-165.

53. Bickford RG, Butt HR. Hepatic coma: the electroencephalography pattern. J Clin Invest 1955;34:790-799.

54. Fountain NB, Waldman WA. Effects of benzodiazepines on triphasic waves: implications for nonconvulsive status epilepticus. J Clin Neurophysiol 2001;18:345-352.

55. Boulanger JM, Deacon C, Lecuyer D, Gosselin S, Reiher J. Triphasic waves versus nonconvulsive status epilepticus: EEG distinction. Can J Neurol Sci 2006;33:175-180. 